\title{
CAPITALISMO DE PLATAFORMAS (2018)
}

Nick Srnicek. Caja Negra.

doi: https://doi.org/10.26439/en.lineas.generales2021.n6.5602

\section{Fernando García Blesa \\ Universidad de Lima}

\begin{abstract}
Queda claro que pedir privacidad al capitalismo de vigilancia o reclamar para que se ponga un fin a la vigilancia comercial en internet es como pedirle a Henry Ford que haga a mano cada uno
\end{abstract} de sus Ford T.

(Zuboff, como se citó en Srnicek, 2018, p. 94)

El capitalismo ha tenido, desde su surgimiento, un rol central en la historia de la humanidad. Uno de los factores que explica este fenómeno es la capacidad que este posee para reinventarse según las diversas circunstancias históricas que la humanidad ha atravesado. El capitalismo, entendido no solo como sistema económico, sino como orden simbólico, tiende a reestructurarse ante las crisis: nuevos significantes, nuevos medios, nuevas tecnologías, nuevas maneras de organización, nuevos tipos de trabajo y nuevos mercados emergen para crear nuevas formas de acumular capital.

En el presente libro, Nick Srnicek desarrolla la tesis de que el capitalismo avanzado del siglo xxI se basa en la extracción de datos como nueva materia prima en un nuevo espacio, la plataforma, que se posiciona como un poderoso modelo de negocio que responde a la necesidad de una infraestructura para detectar, grabar y analizar data.

El primer capítulo del libro analiza minuciosamente tres momentos de la historia reciente del capitalismo que explican y han preparado las condiciones para el capitalismo digital: la respuesta a la recesión de los años setenta, que marca el inicio del desplome de la rentabilidad de las manufacturas en las economías avanzadas; el boom y la caída de los años noventa, cuya principal consecuencia fue el establecimiento de una política monetaria laxa; y, finalmente, la respuesta a la crisis del 2008. Asimismo, en esta sección, los principales planteamientos del autor afirman que hay elementos del capitalismo, como la competencia y la búsqueda de ganancia, que siguen siendo estructurales en el mundo. Sin embargo, señala que, desde la década de 1970, se cambiaron los modelos de empleo seguro por el trabajo flexible y los modelos de negocio austeros. Finalmente, Srnicek agrega un factor adicional, el empleo; en un contexto con altos índices de desempleo a largo plazo y una caída del ahorro personal, muchos trabajadores contemporáneos 
quedaron fuera del empleo formal tradicional, vulnerables a situaciones de explotación por necesidad de ingresos.

En el segundo capítulo, el más extenso del libro, Srnicek desarrolla su propuesta conceptual y explica las diferentes plataformas presentes en el capitalismo digital. Afirma que, en lugar de tener que construir un mercado desde cero, una plataforma proporciona la infraestructura básica para mediar entre diferentes grupos, lo que le da ventaja sobre modelos de negocio tradicionales. Además, al posicionarse a sí misma entre usuarios, se constituye como el terreno sobre el que estos se relacionan y desarrollan sus actividades, lo que les permite no solo documentarlas y acceder a más datos, sino controlar las estructuras de las interacciones.

Adicionalmente, Srnicek señala que las plataformas tienen una tendencia a la monopolización, pues siempre buscan ganar más usuarios, y suelen utilizar subvenciones cruzadas; es decir, una rama de la compañía reduce el precio de un servicio o producto -incluso lo proporciona gratis-, pero la otra rama sube los precios para cubrir las pérdidas. En este capítulo aborda las siguientes plataformas: las publicitarias, las industriales, las de productos y las austeras.

Sobre las plataformas publicitarias, afirma que los datos extraídos pasaron de ser una manera de mejorar los servicios a volverse una manera de recolectar ingresos por publicidad. Por ejemplo, Google y Facebook siguen siendo casi completamente dependientes de este tipo de ingresos: en el primer trimestre del 2016, el $89 \%$ de los ingresos de Google y el 96,6 \% de los de Facebook provenían de anuncios. La web 2.0 está basada más en contenido generado por usuarios que en vidrieras digitales y en interfaces multimedia antes que en texto estático. Esto da pase a que en la economía digital converjan la vigilancia y la actividad lucrativa, lo que lleva a que se hable de "capitalismo de vigilancia".

Por otra parte, las plataformas industriales son aquellas que se conocen como la internet de las cosas (Internet of Things). En su nivel más básico, la internet industrial incluye la inserción de sensores y chips de computadoras en el proceso de producción y de rastreadores en el proceso de logística, todos vinculados entre sí. Sin embargo, ahora también se monitorea la actividad del usuario. En vez de depender de grupos focales o encuestas, los manufactureros esperan desarrollar nuevos productos y diseñar nuevos dispositivos sobre la base del uso de datos extraídos de productos ya existentes, lo que posibilita la customización masiva. El autor anota que, por ejemplo, la empresa de gas natural licuado de General Electric ya está recolectando tantos datos como Facebook.

En relación con las plataformas de productos, Srnicek afirma que son quizá uno de los medios más importantes a través de los cuales las empresas intentan recuperar la tendencia a cero costos marginales en algunos bienes. En el caso musical, luego de la caída de las disqueras por las descargas gratuitas, los servicios de suscripción 
aumentaron la cantidad de usuarios de 8 a 41 millones entre el 2010 y el 2014, y se posicionaron como la fuente de ingresos más importante de la música digital. Por otro lado, las plataformas on demand no están afectando solo al software y a los bienes de consumo, sino a la manufactura. Por ejemplo, la industria de los motores de reacción fue pionera en fabricación aditiva. Para evitar el ingreso de mucha competencia, RollsRoyce introdujo el modelo de bienes como servicios, mediante el cual las aerolíneas no compran el motor, no son propietarias, sino que pagan por el acceso. A su vez, RollsRoyce proporciona el mantenimiento y los repuestos. La conservación de la propiedad les permite introducir sensores en sus productos para acumular datos, combinarlos con información del tráfico aéreo, del clima y, de esta manera, tener mayor conocimiento sobre el desempeño de sus productos para asegurar su ventaja competitiva contra los competidores y desarrollar nuevos modelos.

Finalmente, se encuentran las plataformas austeras, que reciben esta denominación debido a que no son propietarias de activos tradicionales, pero son dueñas del activo más importante: la plataforma de software y análisis de datos. Estas se caracterizan por la subcontratación de sus trabajadores, la tercerización y deslocalización del trabajo. Adicionalmente, presenta el caso de Uber, una plataforma austera construida sobre otras plataformas, pero que cuenta con datos críticos que le permiten identificar a los conductores que trabajan en otros aplicativos y, en China, si acuden a protestas.

El autor concluye esta sección afirmando que el capitalismo se ha apoderado de los datos, y que la plataforma se ha convertido en un medio de control y dominación. En esta línea, las grandes plataformas no son solo propietarias de la información, sino dueñas de las infraestructuras de la sociedad. A su vez, esto ha hecho que emerjan plataformas especializadas en la gestión de datos que controlen las industrias: predominan sobre la fabricación, la logística y el diseño, ya que ponen el espacio básico en el que estas operan.

En el tercer y último capítulo, Srnicek plantea que, debido a su tendencia inherente a la monopolización y la centralización de datos, las plataformas buscan desarrollar mecanismos para excluir a sus competidores: aplicativos que solo funcionan con Android, servicios a los que es obligatorio suscribirse a través de Facebook, etcétera. De esta manera, propone tres tendencias principales que están en proceso de configuración en el capitalismo digital: (1) el aumento del alcance de la extracción y análisis de datos; (2) la focalización de las metas corporativas de crecimiento en un segmento de actividad central; y (3) la canalización de datos a plataformas aisladas. La primera consiste en extender el alcance de la extracción y análisis de datos, que explica las inversiones en la Internet of Things, pues registran los comportamientos diarios, así como los avances en hardware, cuya finalidad es aumentar la velocidad de procesamiento y desarrollar ventajas internas sobre los competidores. La segunda tendencia consiste en que las compañías buscan expandirse alrededor de un segmento central de actividad, 
que escapa a las divisiones tradicionales entre competidores, cadena de suministro o conglomerados, sino que actúan como conexiones que buscan ubicarse en posiciones clave de plataformas, como la incursión de Google y Apple en los sistemas operativos o las batallas por las interfaces. La última tendencia esbozada por el autor consiste en la canalización de la extracción de datos hacia plataformas aisladas, como es el caso de Facebook, que busca evitar que los usuarios tengan que abandonar su ecosistema, es decir que los usuarios vean noticias, videos e historias; envíen mensajes, audios; y compren productos.

Srnicek termina su obra alertando que las desigualdades existentes en ingresos y riqueza se replicarán cada vez más en desigualdades de acceso. Ante esto, asevera que el Estado tiene el poder para combatir las plataformas, no solo desde la acción reguladora: el autor aboga por la creación de plataformas públicas, de propiedad de la ciudadanía y controladas por ella. En este sentido, anota que cualquier esfuerzo o iniciativa de cambio debe comprender el funcionamiento de las plataformas, pues la sociedad es cada vez más dependiente de ellas.

Esta estimulante obra resulta de lectura obligatoria para todo profesional de la sociedad contemporánea, ya sea que pertenezca a la academia o al mundo corporativo, pues presenta un análisis exhaustivo de la nueva gran infraestructura social: la plataforma. Sin duda, la pandemia del coronavirus ha acelerado de manera inimaginable el desarrollo del capitalismo digital, forzando la migración de casi la totalidad de la actividad humana a las plataformas, que ahora cuentan con una cantidad soñada de datos: desde compras de supermercado y menús de restaurantes, hasta sesiones de clase y audiencias judiciales. 